\title{
Different medico legal issues in deaths due to entrapment with animal electric traps; a study on selection of cases from the Southern Province, Sri Lanka
}

\author{
Warushahennadi $\mathbf{J}^{1}$, Senavirathne $\mathbf{A S}^{2}$ \\ ${ }^{\prime}$ Department of Forensic Medicine, Faculty of Medicine, University of Ruhuna, Galle, Sri Lanka. \\ ${ }^{2}$ District General Hospital, Matara, Sri Lanka. \\ Correspondence: Dr. Janaki Warushahennadi \\ e-mail: janakiwh@gmail.com \\ (D) https://orcid.org/0000-0002-6880-5513 \\ Submitted on 15.06.2020 and accepted for publication on 11.12.2020
}

\begin{abstract}
Introduction: Deaths due to electrocution involve both low and high voltage current and the manner of death is almost always accidental. Deliberate electrocution of wild animals by an unsafe extension of an electric line is made by drawing an electric connection from the low voltage utility bare lines. The entrapment of humans in these electric traps is observed in several geographical areas in Sri Lanka. The study intends to raise different medico legal issues pertaining to these deaths in a selected sample.
\end{abstract}

Methods: A descriptive, retrospective study was carried out on 13 outdoor electrocution deaths due to contact with animal electric traps. The medico legal autopsies were carried out by the researchers and the data were collected from the autopsy and scene visit findings, police reports and the inquirers' reports.

Results: All the victims were adult males. The electric entry mark which is the hallmark of forensic diagnosis of electrocution was observed in all 13 dead bodies. It was characterised by a groove with charring at the base in 12 deaths. The macroscopic and microscopic features of electrocution were observed even in severely decomposed bodies. The cause of death was in all cases was determined as electrocution and the manner of death was determined as accidental. The trappers in 9 incidences were identified but none of them were prosecuted for breaching the laws of the Electricity Act or the Fauna and Flora Protection Ordinance of Sri Lanka.

Conclusions: The scene visit examination was helpful to determine the manner of death and was determined as accidental which may be debatable according to the law of the country.

\section{Introduction}

Deaths due to electrocution involve both low and high voltage currents. But most of the deaths are due to low voltage current which is AC $220-240 \mathrm{~V}$ in Sri Lanka (1). The manner of death due to electrocution is almost always accidental while the suicides and accidents are rare or uncommon $(1,2)$. The common circumstances for accidental electrocution are household accidents and work related accidents. A 5 year review of different facets of electrocution in India revealed that $14.9 \%$ of the total 5,431 deaths were due to contact with non-insulated wires in public places or in farms for keeping the animals away (3).

In Sri Lanka, different methods are used for hunting wild animals for food and to protect crops which include different types of traps such as locally made gun traps. Another hunting method is using electric traps. Live non-insulated electric cables are laid across the known trails of animals with one end of the cable connected to the low voltage $(230 \mathrm{~V})$ utility bare lines with a metal hook ("Pahankokka"). 
Knowing that the act is illegal, the trappers connect the electric current in the late evening and disconnect by the early morning. These electric trapping for hunting wild animals are observed in several geographical regions of Sri Lanka including several rural areas of Galle and Matara districts of the Southern province. The worst scenario of these electric traps is the entrapment of humans causing fatalities. Recovering of these dead bodies in outdoor trapping is usually late leading to several medico legal issues arising for the forensic pathologist. Furthermore, the alteration and removing the evidence from the scene causes great difficulties to the investigators. The medico legal issues related to these deaths affect the interpretation of the autopsy findings, determination of the cause and the manner of death.

This study intends to discuss different medico legal issues pertaining to the deaths due to entrapment in animal electrical traps. We hope that this study will serve as an eye opener for the legal and administrative authorities in the relevant fields who can contribute to prevent this illegal activity and thereby to prevent these electrocution deaths.

\section{Methods}

This descriptive, retrospective study was carried out on 13 selected outdoor electrocution deaths due to contact with animal electric traps. The autopsies of these 13 deaths were carried out by the researchers during the period of August 2018 to October 2019 at Base Hospital, Elpitiya and District General Hospital, Matara, in the Southern Province of Sri Lanka. In each case, a meticulous medico legal autopsy was performed following an Inquest. The sections of the skin from the entry mark were obtained for histological examination as a routine procedure of the autopsy examination to determine the cause of death. The data were collected from the post mortem records, histology reports and the crime scene examination records including the crime scene photographs. The data was also obtained from the investigating police records and the reports of the Inquirers into deaths.

The cases were evaluated in terms of age, gender, relationship of the deceased with the trapper, type and anatomical distribution of electric injuries, macro and microscopic features of injuries and scene visit findings. All the data were coded and entered into data base created using SPSS (version 17.0) preserving the anonymity of the subjects and was analysed. The Ethical approval was obtained from the Ethics Review Committee, Faculty of Medicine, University of Ruhuna.

\section{Results}

All the victims were males and the age ranged from 17 to 75 years and the 6 out of the total were in the 50 to 75 year age range. When the relationship of the deceased victims with the trapper was concerned, 2 were trappers themselves, 4 were friends of the trappers while the rest (7) did not have any relationship with the animal trapper.

In one incident, there were three victims at the same scene and out of them, one person was the trapper himself and the other two were his friends.

The bodies were recovered from the original scene in 12 cases and one dead body had been removed from the original scene and was recovered from a marshy land several kilometers away. Nine dead bodies were located in abandoned marshy lands and two were found in paddy fields and one was found in a cinnamon cultivated land respectively.

The scene visit examination findings were used to understand the uniform mechanism of laying the electric cable traps. According to the 6 case findings where the cables were present at the scene; uninsulated cables have been laid around $10-12 \mathrm{~cm}$ above the ground level. Wooden sticks have been erected on the ground randomly to fix the cables above the ground level. One end of the cable was fixed to the low voltage utility bare lines using metal hooks.

Out of the 12 dead bodies which were recovered from the original scene, the electric cables were identified firmly gripping in the hands of the deceased in 5 cases and in one case the cable was lying on the ground (Figure 1). In 6 cases the cables had been removed by the time of the examination of the scene, but there were evidence of trapping such as presence of bundles of sticks or randomly erected sticks at the scene (Figure 2).

The bodies were in different stages of decomposition. While 3 dead bodies were fresh, 4 in early 3 in moderate (Figure 3 ) and 3 in advanced 
states of decomposition. All the victims were identified by the relatives from the facial features, clothing and personal belongings.

The electric entry mark was present in all 13 victims. It was characterised by an elongated groove varying in length (Figure 4) in all cases. The base of the groove was charred in 12 cases and puckering of the surrounding skin with elevation of the margins were observed in 6 cases. When the part of the body affected was concerned, the electric entry marks were present on the upper limbs and lower limbs in 6 cases each and on the chest wall in one case (Table 1). The exit electric mark was absent in all 13 victims.

The histopathology of the electric entry marks revealed carbonization of the epithelium in all cases. There was dermo-epidermal separation in 12 cases and the elongation of cell nuclei of basal layer of epidermis was observed in 5 cases (Figure 5).

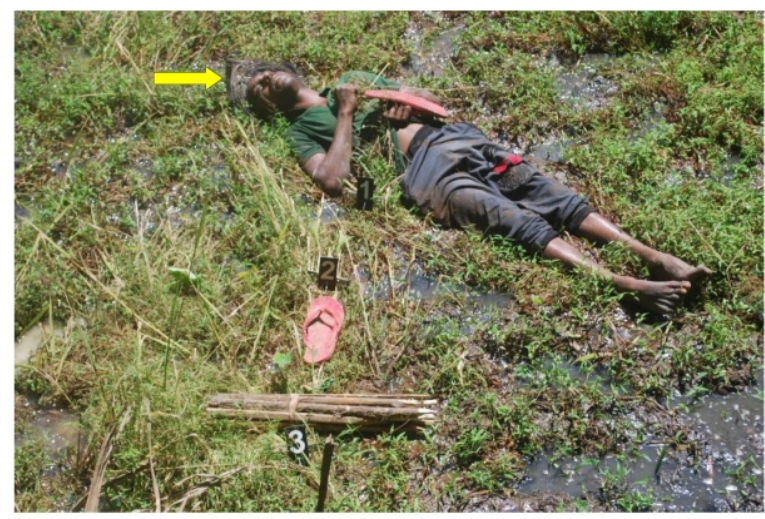

Figure 1: Body at the scene. Note the bundle of sticks and a roll of cable around the head shown with the arrow.

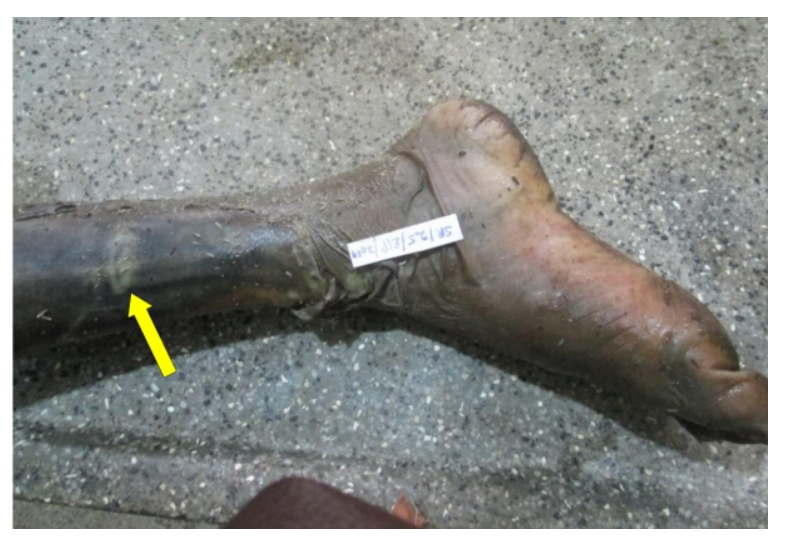

Figure 2: Electric mark on the leg. Note severe decomposition with peeling off of the skin

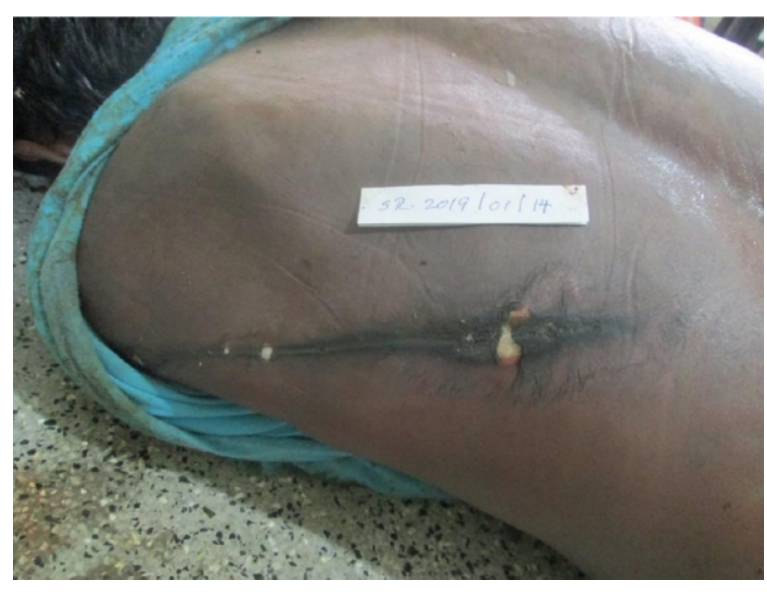

Figure 3: Elongated groove on the back of chest.

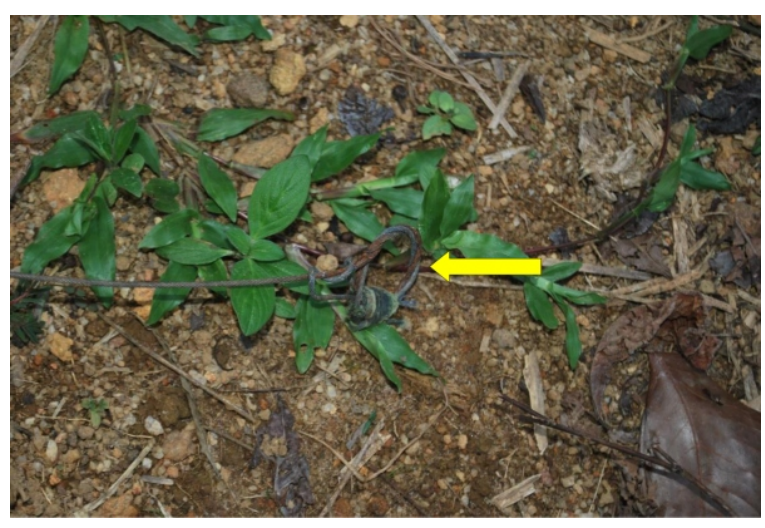

Figure 4: Close up photograph of cable with a hook at the scene.

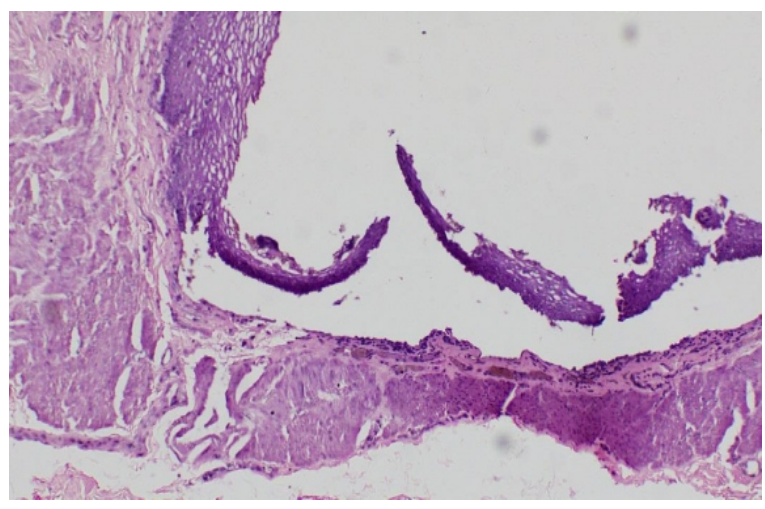

Figure 5: Photomicrograph of electric mark. Note grooving, epithelial carbonization, dermo-epidermal separation. 
Table 1: Macroscopic features of electric entry mark in 13 cases

\begin{tabular}{llccl}
\hline & Site of injury & Charring & Puckering & Decomposition state \\
\hline 1 & Back of both ankles & $\times$ & $\times$ & Moderate \\
2 & Inner aspect of the left wrist & $\checkmark$ & $\checkmark$ & Fresh \\
3 & Front of both thighs & $\checkmark$ & $\times$ & Advanced \\
4 & Right palm & $\checkmark$ & $\checkmark$ & Fresh \\
5 & Back of right calf & $\checkmark$ & $\times$ & Fresh \\
6 & Back of chest & $\checkmark$ & $\times$ & Moderate \\
7 & Left thigh & $\checkmark$ & $\times$ & Moderate \\
8 & Back of right forearm & $\checkmark$ & $\checkmark$ & Early \\
9 & Left palm & $\checkmark$ & $\checkmark$ & Early \\
10 & Right palm & $\checkmark$ & $\checkmark$ & Early \\
11 & Back of right knee & $\checkmark$ & $\checkmark$ & Early \\
12 & Left thigh & $\checkmark$ & $\times$ & Advanced \\
13 & Back of right shoulder & $\checkmark$ & $\times$ & Advanced \\
\hline
\end{tabular}

There were no other antemortem injuries on the bodies. There were postmortem injuries due to animal attacks with removal of distal parts of the body which was in advanced state of decomposition.

The cause of death was determined as electrocution and the manner of death was determined as accidental. The cause and the manner of death in all cases were determined considering the typical scene visit findings, presence of macroscopic and microscopic features of electric mark and excluding the other injuries and any pathological conditions on the body which could have caused death. The trappers in 9 incidences were identified and were produced to the court of law by the police. They were bailed out after been filed cases in the Magistrate Courts. None of the cases were directed to the High Courts.

\section{Discussion}

The major medico legal issues which needed to be addressed in this study were the interpretation of the findings at autopsy, arriving at the cause of death and the manner of death. The diagnosis of deaths due to electrocution is commonly based on the morphological findings, circumstances of the death and above all the electric mark which is the hallmark for forensic diagnosis of electrocution $(4,5)$. The electric entry mark or Joule burn due to contact with the domestic electric current has classical macroscopic as well as microscopic features. Macroscopically it is a thermal burn, characterised by a collapsed crater with grey or white ring or an elongated linear groove with elevated margins (6). It may reproduce the shape of the conductor and when there is a linear wire, the mark will be an elongated groove with elevated margins (7). The mark in all victims in the study was a groove which supports the electrocution.

The important finding in this study was that the electric entry mark was able to be observed even on moderate to severe decomposed bodies. Therefore the electric entry marks on the body is a valuable and identifiable macroscopic finding even in decomposed bodies to suggest electrocution.

The microscopic findings of electric mark includes thermal denaturation of collagen causing it to stain blue with haematoxylin, separation of microblisters within squamous epithelium forming intraepidermal and epidermo-dermal separation, 
stretching and narrowing of the contours of the nuclei of epithelial cells resulting in palisading type of appearance and burning and charring of the skin in prolonged contact with electric current $(3,8)$. In our study sample, the epithelial carbonization was observed in all 13 cases and dermo-epidermal separation in 12 cases. An important observation of this study was that even in decomposed bodies the microscopic features of electric entry mark was identifiable where the epidermis has peeled off due to the process of decomposition

Entry mark around the knees and legs were compatible with the primary contact while trespassing the live cables which was able to interpret after the examination of the scene. Injuries in the fingers and the finger webs were of injuries of gripping the cables. It was evident in two cases where the cable was held in the clenched hands. This is a salient feature of sudden death described as cadaveric spasm which is an instantaneous rigor without preceding post-mortem flaccidity. The precise pathophysiological basis of this phenomenon called cadaveric spasm is still not known but observed in instantaneous unnatural deaths (9).

In most cases of accidental electrocution, injuries present on the hands $(1,3,10)$. But in our study, the majority had the injuries on the lower limbs. The crime scene examinations were useful in observing the mechanism of laying the cables around the field of hunting and to interpret the injury pattern observed on victims. In one crime scene examination, the victim who was the trapper gone to lay the cables, had accidentally trespassed someone else's trap and sustained electrocution. There was a roll of cables and a bundle of sticks near the body. Live cables were not at the scene in six cases which means the offender responsible for laying cables or another person intervened and removed it from the scene. Several bodies have been moved from the original place of deaths. Therefore it is important to visit the crime scene examinations to understand and interpret different medico legal issues in forensic practice.

The cause of death was ascertained as electrocution after considering the findings of the crime scene investigations, presence of macro and microscopic features of electrocution, absence of other injuries or pathology at the autopsy.
The manner of death in all cases was concluded as accidental which might be debatable. The culprits have committed several offences. The Fauna and Flora Protection Ordinance of Sri Lanka provides for the protection, conservation and preservation of the fauna and flora of Sri Lanka. The Section 30 of the Ordinance which describes the offences related to mammals and reptiles state "causing injuries or killing of a mammal using a trap is a punishable offence' (11). Its Sub Section 1 states that several mammals which includes wild pig/ boars, rabbits and porcupines are grouped into the category of pests and the farmers could destroy these pests in their agricultural lands for the purpose of protecting their crops. Such incidences if happens should be reported to the police and the government agent's office of the area by the farmer.

The Electricity Act. No. 20 of 2009 states, licence to generate, transmit and distribute the electricity should be obtained from the Public Utilities Commission of Sri Lanka. The Section 7 of the Act states that without licence no one can generate, transmit and distribute electricity and the Section 49 of the Act states that any person who extracts electricity (which is in the course of distribution by a distribution licence) without license shall be guilty of an offence and liable for conviction after a summary trial before the magistrate (12).

The Section 298 of the Penal Code of Sri Lanka states 'whoever causes the death of any person by doing any rash or negligent act shall be punished with imprisonment, or with a fine or both' (13).

Therefore, the legal actions could be taken against the offenders under the above mentioned statutes. Out of the total number of 10 offenders in this study, 9 have been identified by the police and were produced before the courts and bailed out. None of the cases have been directed to the High Courts. None of the accused have been prosecuted for breaching the laws of the Electricity Act or the Fauna and Flora Protection Ordinance of Sri Lanka.

\section{Conclusions}

The morphology of electric entry marks is a hallmark of electrocution in the study sample and features were preserved even in decomposed bodies. There are legal provisions in Sri Lanka to prevent this 
electrocution deaths, therefore the relevant authorities has a duty to be more proactive in exercising the legislative powers.

\section{Limitations}

Small sample size is the biggest limitation of this study in arriving at several conclusions. The study will be continued further by the researchers as a prospective study to obtain a bigger sample size to arrive at more substantial conclusions.

\section{Acknowledgements}

We would like to acknowledge;

Prof. Lakmini Mudduwa, Professor of Pathology, Department of Pathology, Faculty of Medicine, University of Ruhuna for reviewing the histology slides.

Dr. U.C.P. Perera, Senior Lecturer, Department of Forensic Medicine, Faculty of Medicine, University of Ruhuna for reviewing the Laws in the Penal Code of Sri Lanka.

Mr. R.M. Hettiarachchi, Chartered Electrical Engineer, Branch Manager, Lanka Electricity Company (Pvt.) Ltd., Kotte branch, for reviewing the relevant sections in the Electricity Act of Sri Lanka

Mr. Ajith Gunathunge, Park Warden, Bundala Natural Park, for reviewing the relevant sections of the Fauna and Flora Protection Ordinance of Sri Lanka.

\section{References}

1. Kumar S, Verma A K, Singh U S. Electrocution - related mortality in northern India - A 5 year retrospective study. Egyptian Journal of Forensic Science. 2014; 4: 1-6.

2. Laupland KB, Kortbeek JB, Findlay C, Kirptrick AW, Hameed SM. Population based study of severe trauma due to electrocution in the Calgary Health Region, 1996-2002. Can J Surg. 2005; 48(4): 289-292.
3. Giri S, Waghmode A, Tumran NK. Study of different facets of electrocution deaths: A 5-year review. Egyptian Journal of Forensic Sciences. 2019; 9: 2-6. doi: 10.1186/s41935018-0103-5.

4. Visona SD, Chen Y, Bernardi P, Andrello L, Osculati A. Diagnosis of Electrocution: The application of scanning Electron Microscope and Energy-Dispersive X-ray Spectrography in Five cases. Forensic Sci. Int. 2018; 284: 107-116. doi:10.1016/j.forsciint.2018.01.001

5. Kinoshita H, Jamal M, Kumusashi M, Tsutsui K, Amano K. Findings of current marks: Histopathological examination and energy-dispersive X-ray spectroscopy in three cases. Legal Medicine. 2013;15(5) 283-287.

6. DiMaio VJM, DiMaio D. Forensic Pathology. $2^{\text {nd }}$ Edition. CRC press, 2001: 410-418.

7. Saukko P, Knight B. Forensic Pathology. $4^{\text {th }}$ Edition. CRC press, 2017:319-329.

8. Sangita C, Garima G, Jaynthi Y, Arneet A, Neelkamal K. Histology Indicators of Cutaneous Lesions Caused by Electrocution, Flame Burn and Impact Abrasion. Med Sci Law. 2018; 58(4): 216-221.

doi: $10.1177 / 0025802418776116$

9. Chauhan M, Behera C, Bodwal J, Dikshit PC. Rare gripping object in electrocution: Cadaveric spasm at its best. Med Leg J. 2017; 85(3): 155-158.

doi: $10.1177 / 0025817216688852$.

10. Liu S, Yu Y, Huang Q, Luo B, Liao X. Electrocutionrelated mortality: a review of 71 deaths by low-voltage electrical current in Guangdong, China, 2001-2010. Am JForensic Pathol. 2014;35(3): 193-6.

doi:10.1097/PAF.0000000000000072

11. Fauna and Flora Protection Ordinance of Sri Lanka (Amendment) Acts No. 44 of 19641 of 1970 and 49 of 1993. Section 30.

12. Sri Lanka Electricity Act. No 20 of 2009. Sections 7, 49.

13. Penal Code of the Democratic Socialist Republic of Sri Lanka. Ordinance. No. 2 of 1883 . Section 298. 